University of Nebraska - Lincoln

DigitalCommons@University of Nebraska - Lincoln

3-12-2007

\title{
Thermoeconomics of seasonal latent heat storage system
}

Yaşar Demirel

University of Nebraska-Lincoln, ydemirel2@unl.edu

H. Huseyin Ozturk

Follow this and additional works at: https://digitalcommons.unl.edu/chemengthermalmech

Part of the Heat Transfer, Combustion Commons

Demirel, Yaşar and Ozturk, H. Huseyin, "Thermoeconomics of seasonal latent heat storage system" (2007). Papers in Thermal Mechanics. 10.

https://digitalcommons.unl.edu/chemengthermalmech/10

This Article is brought to you for free and open access by the Chemical and Biomolecular Engineering Research and Publications at DigitalCommons@University of Nebraska - Lincoln. It has been accepted for inclusion in Papers in Thermal Mechanics by an authorized administrator of DigitalCommons@University of Nebraska - Lincoln. 


\title{
Thermoeconomics of seasonal latent heat storage system
}

\author{
Yaşar Demirel $^{1, *, \dagger}$ and H. Hüseyin Öztürk ${ }^{2}$ \\ ${ }^{1}$ Department of Chemical Engineering, Virginia Polytechnic Institute and State University, Blacksburg, VA 24061, U.S.A. \\ ${ }^{2}$ Department of Agricultural Machinery, Faculty of Agriculture, Cukurova University, Adana 01330, Turkey
}

\begin{abstract}
SUMMARY
A simple thermoeconomic analysis is performed for a seasonal latent heat storage system for heating a greenhouse. The system consists of three units that are a set of 18 packed-bed solar air heaters, a latent heat storage tank with $6000 \mathrm{~kg}$ of technical grade paraffin wax as phase-changing material, and a greenhouse of $180 \mathrm{~m}^{2}$. The cost rate balance for the output of a unit is used to estimate the specific cost of exergy for a yearly operation. Based on the cost rate of exergy, fixed capital investment, operating cost, and economic data, approximate cash-flow diagrams have been prepared. The systems feasibility depends on the cost rate of exergy, operating cost, internal interest rate, and rate of taxation strongly. A cash-flow diagram based on exergy considerations may enhance the impact of thermoeconomic analysis in feasibility studies of thermal systems. Copyright (C) 2006 John Wiley \& Sons, Ltd.
\end{abstract}

KEY WORDS: latent heat storage; exergy analysis; thermoeconomics; discounted cash-flow diagram

\section{INTRODUCTION}

Latent heat storage (LHS) is a popular research area with industrial and domestic applications, such as energy recovery of air conditioning (Go et al., 2004), under-floor electric heating (Lin et al., 2005), and greenhouse heating and other applications (Demirel et al., 1993; Demirel and Paksoy, 1993; Ramayya and Ramesh, 1998; Bascetincelik et al., 1999; Rosen and Dincer, 2003; Saman et al., 2005). LHS provides near-isothermal heat storage and recovery, and also, exergy loss in a LHS system is smaller compared with that of sensible heat storage due to the finite differences between fluid temperature and phase-changing material (PCM) under the mechanical equilibrium (Rosen and Dincer, 2003). As solar energy storage system is primarily a waste, clean energy management, it is environmentally friendly.

Thermoeconomic analysis accounts the true potential of energy when it combines the thermodynamic principles with engineering economics to estimate the cost of exergy (Szargut, 1990; Tsataronis, 1993; Erlach et al., 1999; Demirel, 2002; Sciubba, 2003). This study presents the simple cost rate balances for estimating the cost rate of exergy and displays the discounted cash-flow

\footnotetext{
*Correspondence to: Yaşar Demirel, Department of Chemical Engineering, Virginia Polytechnic Institute and State University, Blacksburg, VA 24061, U.S.A.

†E-mail: ydemirel@vt.edu
} 
diagrams (DCFD) based on approximate exergy costs, fixed capital costs, and operating costs for a seasonal LHS system (Demirel et al., 1993; Bascetincelik et al., 1999; Ozturk, 2005). It shows the impact of incorporation of a cash-flow diagram (CFD) in thermoeconomic analysis.

\section{SEASONAL LATENT HEAT STORAGE BY PARAFFIN}

The case study involves a seasonal solar LHS system using paraffin as PCM (Demirel et al., 1993). Figure 2 shows the three basic units that are the solar air heaters, the LHS, and the greenhouse, which are briefly described below.

\subsection{System of packed-bed solar air heaters}

The system has a total solar heat absorbing area of $27 \mathrm{~m}^{2}$ consisting of 18 packed-bed solar air heaters using an air-flow rate of $600 \mathrm{~m}^{3} \mathrm{~h}^{-1}$ (Demirel and Kunç, 1987). Each solar heater has $1.5-\mathrm{m}^{2}$ absorber area with a length of $1.9 \mathrm{~m}$ and width of $0.9 \mathrm{~m}$. Raschig ring type of packing made of polyvinyl chloride with the characteristic diameter of $0.05 \mathrm{~m}$ is used within the air-flow passage. The packing enhances the wall-to-fluid heat transfer mainly by increasing the radial and axial mixing as well as reducing the wall heat-transfer resistance (Demirel, 1989; Ozturk and Demirel, 2004).

\subsection{Latent heat storage unit}

The solar energy is stored in a horizontal steel tank, $1.7 \mathrm{~m}$ long and $5.2 \mathrm{~m}$ wide, containing $6000 \mathrm{~kg}$ of technical grade of paraffin wax as PCM. Paraffin wax consists of mainly straightchain hydrocarbons $(>75 \%)$ and very little amount of branching. Commercial waxes may have a range of about $8-15$ carbon-number with a volume contraction less than $12 \%$ during freezing. The tank is insulated with $0.05 \mathrm{~m}$ of glass fibre wool. Inside the paraffin, there are two embedded spiral coils made of perforated polyethylene pipes with a total length of $97 \mathrm{~m}$ and diameter of $0.1 \mathrm{~m}$. The coils carry the warm air-flow pumped from solar air heaters as well as the cold air from the greenhouse. Differential scanning calorimeter measurements show that the paraffin has a melting temperature range of $48-60^{\circ} \mathrm{C}$ and approximately $190 \mathrm{~kJ} \mathrm{~kg}^{-1}$ of latent heat of melting. Paraffin wax freeze without supercooling, and melt without segregation.

\subsection{Greenhouse}

The greenhouse with an area of $180 \mathrm{~m}^{2}$ and a height of $3 \mathrm{~m}$ is covered by $0.35 \mathrm{~mm}$ thick polyethylene, and is aligned north-to-south. Heat storage unit connects the solar air heater system to the greenhouse with appropriate fans, valves and piping. Whenever the temperature in the greenhouse drops below a set point, a fan circulates the air from the greenhouse through the PCM until the greenhouse temperature reaches an acceptable level. 


\section{THERMOECONOMIC ANALYSIS OF THE LHS SYSTEM}

Thermoeconomic analysis combines exergy analysis with economic analysis, and calculates the efficiencies and costs based on exergy. The exergy and the cost analyses are briefly described below.

\subsection{Exergy analysis}

Accessible work potential is called the exergy that is the maximum amount of work that may be performed theoretically by bringing a resource into equilibrium with its surrounding through a reversible process. Exergy is always lost by irreversibilities in a system. For an incompressible gas initially at temperature $T_{\mathrm{i}}$ with constant heat capacity, the exergy is a simple function of temperatures when the pressure change is negligible

$$
\dot{X}=\dot{m} C_{p}\left[\left(T_{\mathrm{i}}-T_{\mathrm{o}}\right)-T_{\mathrm{o}} \ln \left(\frac{T_{\mathrm{i}}}{T_{\mathrm{o}}}\right)\right]
$$

where $C_{p}$ is the specific heat and $T_{\mathrm{o}}$ is the reference (dead state) temperature.

The exergy balance and the exergy loss is given by

$$
\sum_{\text {into system }}\left[\dot{m} X+\dot{Q}\left(1-\frac{T_{\mathrm{o}}}{T_{\mathrm{s}}}\right)+\dot{W}_{\mathrm{s}}\right]-\sum_{\text {out of system }}\left[\dot{m} X+\dot{Q}\left(1-\frac{T_{\mathrm{o}}}{T_{\mathrm{s}}}\right)+\dot{W}_{\mathrm{s}}\right]=\dot{X}_{\text {loss }}
$$

where $\dot{W}$ is the work rate. The terms in square parenthesis show the exergy accompanying mass, heat, and work, respectively, while $\dot{X}_{\text {loss }}$ represents the exergy loss. If a system undergoes a spontaneous change to the dead state without a device to perform work, then exergy is completely lost. Therefore, exergy is a function of both the physical properties of a resource and its environment.

Figure 1 shows the temperature profiles in charging and discharging operations for the countercurrent LHS with limited sensible heating and cooling of the paraffin. An optimum LHS system stores and recovers exergy with as little as possible exergy losses. The warm air from the solar air heater system heats the PCM, which may initially be at a temperature $T_{\mathrm{sc}}$ lower than the temperature at which the melting starts. After a while, the paraffin melts completely, and may eventually reach to a temperature $T_{\mathrm{sh}}$ after sensible heating. Therefore, the paraffin undergoes a temperature difference of $T_{\mathrm{sh}}-T_{\mathrm{sc}}$, as shown in Figure 1.

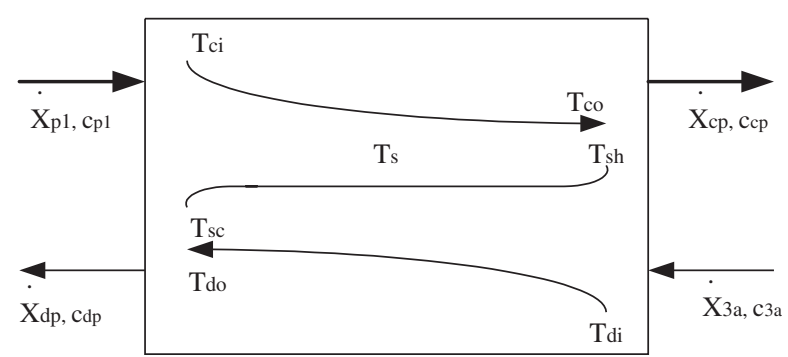

Figure 1. Typical temperature profiles of a LHS system for charging (c) and discharging (d) operations. 
For a yearly operation, the solar heat recovered by the solar air heater system for charging the paraffin would be

$$
\dot{Q}_{\mathrm{c}}=\dot{m}_{\mathrm{c}} C_{\mathrm{pc}}\left(T_{\mathrm{ai}}-T_{\mathrm{ao}}\right)
$$

where $\dot{m}_{\mathrm{c}}$ is the charging fluid mass flow rate, $T_{\mathrm{ai}}$ is the air inlet temperature, which is practically equal to ambient air temperature, while $T_{\text {ao }}$ is the temperature of the warm air leaving the solar air heater system. A part of the solar energy recovered will be stored by the paraffin $\left(Q_{\mathrm{s}}\right)$ with sensible heating and sensible cooling effects

$$
Q_{\mathrm{s}}=m_{\mathrm{s}}\left[C_{p \mathrm{~S}}\left(T_{1}-T_{\mathrm{sc}}\right)+\Delta H_{\mathrm{m}}+C_{p \mathrm{~L}}\left(T_{\mathrm{sh}}-T_{\mathrm{h}}\right)\right]
$$

where $\Delta H_{\mathrm{m}}$ is the heat of melting, $T_{1}$ and $T_{\mathrm{h}}$ are the lowest and highest melting points of the paraffin, and $C_{p \mathrm{~S}}$ and $C_{p \mathrm{~L}}$ are the specific heats of solid and liquid states of paraffin, respectively. Equation (5) represents the seasonal heat storage starting with a subcooled solid temperature of $T_{\mathrm{sc}}$, and finally ending with a superheated temperature of $T_{\mathrm{sh}}$ of liquid PCM. The lost solar energy that is not stored would be

$$
\dot{Q}_{\text {loss }}=\dot{Q}_{\mathrm{c}}-\dot{Q}_{\mathrm{s}}
$$

The rate of exergy stored by the paraffin is

$$
\dot{X}_{\mathrm{s}}=\dot{Q}_{\mathrm{s}}\left(1-\frac{T_{\mathrm{o}}}{T_{\mathrm{s}}}\right)
$$

where $T_{\mathrm{s}}$ is an average temperature of the paraffin, which may be approximated by $\left(T_{\mathrm{sc}}+T_{\mathrm{sh}}\right) / 2$.

Assuming that the air pressure changes are negligible, the net rate of exergy transfer to the paraffin from the charging fluid is

$$
\Delta \dot{X}_{\mathrm{c}}=\left(\dot{X}_{\mathrm{ci}}-\dot{X}_{\mathrm{co}}\right)=\dot{m}_{\mathrm{c}} C_{p \mathrm{c}}\left[\left(T_{\mathrm{ci}}-T_{\mathrm{co}}\right)-T_{\mathrm{o}} \ln \left(\frac{T_{\mathrm{ci}}}{T_{\mathrm{co}}}\right)\right]
$$

The exergy efficiency of the LHS is the ratio of the stored exergy rate to the supplied exergy rate by the solar air heater system

$$
\eta=\frac{\dot{X}_{\mathrm{s}}}{\dot{X}_{\mathrm{ao}}}
$$

where

$$
\dot{X}_{\mathrm{ao}}=\dot{m}_{\mathrm{c}} C_{\mathrm{pc}}\left[\left(T_{\mathrm{ao}}-T_{\mathrm{o}}\right)-T_{\mathrm{o}} \ln \left(\frac{T_{\mathrm{ao}}}{T_{\mathrm{o}}}\right)\right]
$$

It is assumed that the PCM is totally melted and heated to a temperature $T_{\text {sh }}$ when discharging fluid starts recovering heat estimated by (see Figure 1)

$$
\dot{Q}_{\mathrm{d}}=\dot{m}_{\mathrm{d}} C_{p \mathrm{~d}}\left(T_{\mathrm{di}}-T_{\mathrm{do}}\right)
$$

The heat gained by the discharging fluid will be lost by the PCM, and the exergy change of the discharging fluid would be

$$
\Delta \dot{X}_{\mathrm{d}}=\left(\dot{X}_{\mathrm{di}}-\dot{X}_{\mathrm{do}}\right)=\dot{m}_{\mathrm{d}} C_{p \mathrm{~d}}\left[\left(T_{\mathrm{di}}-T_{\mathrm{do}}\right)-T_{\mathrm{o}} \ln \left(\frac{T_{\mathrm{di}}}{T_{\mathrm{do}}}\right)\right]
$$

where $\dot{m}_{\mathrm{d}}$ is the mass flow rate of discharging fluid. 


\subsection{Cost analysis}

Flows leaving a unit that is a subsystem with control volume are considered as products. For any unit or a subsystem, the specific cost of exergy $c$ for entering or exiting streams is

$$
c=\dot{C} / \dot{X}
$$

where $\dot{C}$ and $\dot{X}$ are the cost rate and the rate of exergy transfer for a stream, respectively. However, the total cost of a product and other exiting streams would include the fixed capital investment $C_{i, \mathrm{~F}}$, and annual operating cost of equipment $\dot{C}_{i, \mathrm{OP}}$ for a unit $i$. Then the cost rate balance for a single unit $i$ is

$$
\left(\sum_{j} c_{j} \dot{X}_{j}\right)_{\text {out }}=\left(\sum_{j} c_{j} \dot{X}_{j}\right)_{\text {in }}+C_{i, \mathrm{~F}}+\dot{C}_{i, \mathrm{OP}}+\dot{C}_{i, \text { loss }}
$$

where $c_{j}$ is the specific cost of stream $j$ in $\$ \mathrm{~kW}^{-1}$-year ${ }^{-1}, X_{j}$ is the rate of exergy of stream $j$ in $\mathrm{kW}$-year, $\dot{C}_{i, \text { loss }}$ is the loss due to heat-transfer interactions between a unit and its surroundings.

Figure 2 shows a structural diagram (Valero et al., 1994) of the complete seasonal LHS with the three units. All the work interactions for fans, valves and pressure changes in ach unit are assumed to be negligible. From Equation (12), we have the cost rate balance for the product of warm air to be used in charging the paraffin

$$
c_{\mathrm{p} 1} \dot{X}_{\mathrm{p} 1}=c_{\mathrm{a}} \dot{X}_{\mathrm{a}}+c_{\mathrm{se}} \dot{X}_{\mathrm{se}}+C_{1, \mathrm{~F}}+\dot{C}_{1, \mathrm{OP}}+c_{1, \text { loss }} \dot{X}_{1, \text { loss }}
$$

where $c_{i}$ is the specific cost, and $X_{i}$ is the rate of exergy. The subscripts $\mathrm{p} 1$ and a are the product 1 and the air, respectively, while se is the solar energy. The terms $C_{1, \mathrm{~F}}$ and $\dot{C}_{1, \mathrm{OP}}$ are the fixed capital cost and operating cost, respectively, of the solar air heater system. $\dot{X}_{1, \text { loss }}$ is the total exergy loss through the solar heater system. The operating cost is usually $20 \%$ of the fixed capital cost. The specific costs of ambient air and solar energy are assumed to be zero. Therefore, the specific cost of warm air as product 1 of unit 1 is

$$
c_{\mathrm{p} 1}=\frac{C_{1, \mathrm{~F}}+\dot{C}_{1, \mathrm{OP}}}{\dot{X}_{\mathrm{p} 1}}+c_{1, \mathrm{loss}}\left(\frac{\dot{X}_{1, \mathrm{loss}}}{\dot{X}_{\mathrm{p} 1}}\right)
$$

where

$$
\dot{X}_{\mathrm{p} 1}=\dot{m}_{1} C_{p}\left[\left(T_{\mathrm{p} 1}-T_{\mathrm{o}}\right)-T_{\mathrm{o}} \ln \left(\frac{T_{\mathrm{p} 1}}{T_{\mathrm{o}}}\right)\right] \quad \text { and } \quad \dot{X}_{1, \mathrm{loss}}=\dot{Q}_{1, \operatorname{loss}}\left(1-\frac{T_{\mathrm{o}}}{T_{1 \mathrm{~s}}}\right)
$$

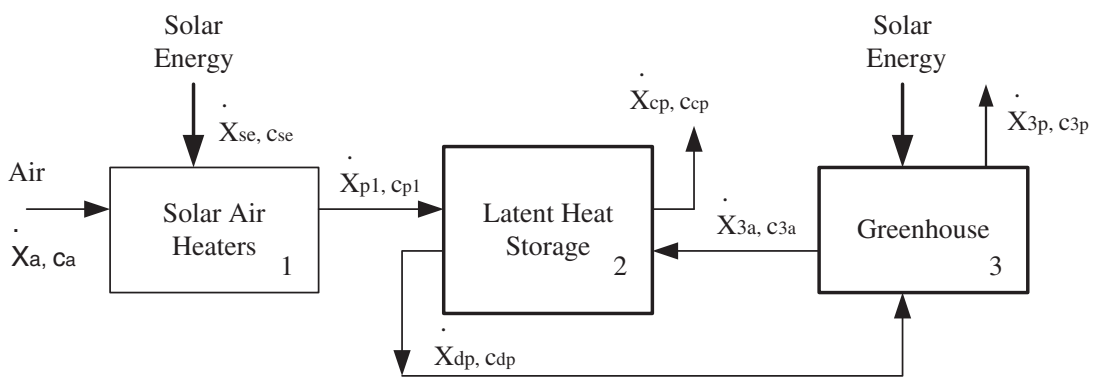

Figure 2. Three units of the solar heat storage by phase-changing material of paraffin. (The exergy losses of the units are accounted in the analysis.) 
$T_{1 \mathrm{~s}}$ is the surface temperature of the solar heater unit, and $\dot{Q}_{1 \text {,loss }}$ is the solar energy loss from the solar air heater system to the surroundings.

We can operate the LHS in charging and discharging modes. The cost rate balance for charging is

$$
c_{\mathrm{cp}} \dot{X}_{\mathrm{cp}}=c_{\mathrm{p} 1} \dot{X}_{\mathrm{p} 1}+C_{2, \mathrm{~F}}+\dot{C}_{2, \mathrm{OP}}+c_{2, \text { loss }} \dot{X}_{2, \text { loss }}
$$

where $\dot{C}_{2, \mathrm{OP}}$ and $\mathrm{C}_{2, \mathrm{~F}}$ are the yearly operating cost and the fixed capital cost of the LHS system, which includes the paraffin, the tank with the coils and the insulation. The total exergy loss for the LHS $\dot{X}_{2, \text { loss }}$ accounts for both the charging and discharging operations. For a yearly operation, the total rate of exergy for charging is assumed to be equal to the rate of exergy stored by the paraffin $\left(\dot{X}_{\mathrm{cp}}=\dot{X}_{\mathrm{s}}\right)$. Then the specific costs of air leaving the LHS (unit 2) as charging product, $\mathrm{cp}$ is

$$
c_{\mathrm{cp}}=c_{\mathrm{p} 1}\left(\frac{\dot{X}_{\mathrm{p} 1}}{\dot{X}_{\mathrm{s}}}\right)+\frac{C_{2, \mathrm{~F}}+\dot{C}_{2, \mathrm{OP}}}{\dot{X}_{\mathrm{s}}}+c_{2, \text { loss }}\left(\frac{\dot{X}_{2, \text { loss }}}{\dot{X}_{\mathrm{s}}}\right)
$$

By using the exergy efficiency defined in Equation (8) $\eta=\dot{X}_{\mathrm{s}} / \dot{X}_{\mathrm{p} 1}$ in Equation (16), we have

$$
c_{\mathrm{cp}}=c_{\mathrm{p} 1}\left(\frac{1}{\eta}\right)+\frac{C_{2, \mathrm{~F}}+\dot{C}_{2, \mathrm{OP}}}{\dot{X}_{\mathrm{s}}}+c_{2, \text { loss }}\left(\frac{\dot{X}_{2, \text { loss }}}{\dot{X}_{\mathrm{s}}}\right)
$$

As $\eta<1$, the specific cost of charging will be higher that the specific cost of exergy rate transferred from the solar air heater system, and is a function of exergy efficiency $\eta$.

The cost rate balance for the discharging mode is

$$
c_{\mathrm{dp}} \dot{X}_{\mathrm{dp}}=c_{\mathrm{cp}} \dot{X}_{\mathrm{cp}}+c_{3 \mathrm{a}} \dot{X}_{3 \mathrm{a}}+\dot{C}_{2, \mathrm{OP}}
$$

In Equation (18), only the operating cost involving the discharging is used, as the fixed capital cost is already accounted for charging. Also, the exergy loss is not added as it is already accounted within the charging cost analysis. For a yearly operation, the rate of exergy of discharging air is equal to the total rate of exergy stored by the paraffin $\left(\dot{X}_{\mathrm{dp}}=\dot{X}_{\mathrm{s}}=\dot{X}_{\mathrm{cp}}\right)$ by assuming that all the exergy stored is recovered with negligible exergy losses. The specific cost of air leaving the LHS (unit 2) as discharging product, dp is

$$
c_{\mathrm{dp}}=c_{\mathrm{cp}}+c_{3 \mathrm{a}}\left(\frac{\dot{X}_{3 \mathrm{a}}}{\dot{X}_{\mathrm{s}}}\right)+\frac{\dot{C}_{2, \mathrm{OP}}}{\dot{X}_{\mathrm{s}}}+c_{2, \text { loss }} \frac{\dot{X}_{2, \text { loss }}}{\dot{X}_{\mathrm{s}}}
$$

where

$$
\dot{X}_{3 \mathrm{a}}=\dot{m}_{3 \mathrm{a}} C_{p}\left[\left(T_{3 \mathrm{a}}-T_{\mathrm{o}}\right)-T_{\mathrm{o}} \ln \left(\frac{T_{3 \mathrm{a}}}{T_{\mathrm{o}}}\right)\right]
$$

The cost rate balance around the greenhouse shown in Figure 2 is

$$
c_{\mathrm{p} 3} \dot{X}_{\mathrm{p} 3}+c_{3 \mathrm{a}} \dot{X}_{3 \mathrm{a}}=c_{\mathrm{dp}} \dot{X}_{\mathrm{dp}}+c_{\mathrm{se}} \dot{X}_{\mathrm{se}}+C_{3, \mathrm{~F}}+\dot{C}_{3, \mathrm{OP}}+c_{3, \text { loss }} \dot{X}_{3, \text { loss }}
$$

where $\dot{C}_{3, \mathrm{OP}}$ and $C_{3, \mathrm{~F}}$ are the operating cost the fixed capital cost of the greenhouse. Assuming that $c_{\mathrm{se}}=0$, we have the specific cost of air inside the greenhouse at a required temperature

$$
c_{\mathrm{p} 3}=\frac{1}{\dot{X}_{\mathrm{p} 3}}\left(c_{\mathrm{dp}} \dot{X}_{\mathrm{s}}+C_{3, \mathrm{~F}}+\dot{C}_{3, \mathrm{OP}}-c_{3 \mathrm{a}} \dot{X}_{3 \mathrm{a}}+c_{3, \text { loss }} \dot{X}_{3, \text { loss }}\right)
$$

where

$$
\dot{X}_{\mathrm{p} 3}=\dot{m}_{\mathrm{p} 3} C_{p}\left[\left(T_{\mathrm{p} 3}-T_{\mathrm{o}}\right)-T_{\mathrm{o}} \ln \left(\frac{T_{\mathrm{p} 3}}{T_{\mathrm{o}}}\right)\right]
$$


Inserting Equations (14), (17), and (19) into Equation (21), the specific cost of the air suitable for conditioning the greenhouse becomes

$$
c_{\mathrm{p} 3}=\frac{1}{\dot{X}_{\mathrm{p} 3}}\left(\sum_{i=1}^{3} C_{i, \mathrm{~F}}+\sum_{i=1}^{3} \dot{C}_{i, \mathrm{OP}}+\sum_{i=1}^{3} \dot{C}_{i, \mathrm{loss}}+\dot{C}_{2, \mathrm{OP}}\right)
$$

where $\dot{C}_{i, \text { loss }}$ is the cost rate due to exergy loss of a unit $i$.

\section{RESULTS AND DISCUSSIONS}

Thermoeconomic of the LHS system involves fixed capital investments, operational costs, and exergy costs. It is difficult to estimate the fixed capital and operating costs precisely, since the costs of fuel and equipment change with time. An engineering cost index (Turton et al., 2003) is used to estimate the approximate costs of the solar air heater, and the steel tank where the paraffin is placed. The cost of the greenhouse is approximated by using the $0.35 \mathrm{~mm}$ thick polyethylene cover sheet and aluminium construction. The operating costs are assumed to be $20 \%$ of the fixed capital costs for the solar air heating system and the greenhouse. The relatively lower operating costs for the charging and discharging are assumed as $10 \%$ of the fixed capital cost of the storage tank that are the cost of the steel tank, the paraffin with the corrugated polyvinyl chloride coils inside, and the fibre glass wool insulation outside the tank.

Yearly revenues and savings are calculated as the solar exergy gain through the solar air heaters

$$
X_{\mathrm{se}}=I\left(1-\frac{T_{\mathrm{o}}}{T_{\mathrm{ss}}}\right)
$$

where $T_{\mathrm{ss}}$ is the surface temperature of the Sun and assumed to be $5800 \mathrm{~K}$, and $I$ is the solar radiation. Using an average sunshine period of $2624 \mathrm{~h} \mathrm{year}^{-1}$, and average solar radiation intensity of $3.67 \mathrm{~kW} \mathrm{~h} \mathrm{~m}^{-2}$ per day in Adana, Turkey, the average yearly rates of the transferred and stored heat in the LHS unit are 236.5 and $179.3 \mathrm{~kW}$, respectively (Ozturk, 2005). On the other hand, the approximate yearly average exergy transferred and stored are 12.4 and $8.8 \mathrm{~kW}$ (Ozturk, 2005). The average value of the stored exergy is used in the cost rate calculations in Equations (19) and (21). The working capital is assumed to be approximately $10 \%$ of the total fixed capital cost excluding the cost of land. Approximate cost data and other economic parameters are tabulated in Table I. It is assumed that the three basic units of the seasonal LHS system (Figure 2) constructed after one year. Table II shows the accumulated discounted cash data over a 12-year useful life of the LHS operation with depreciation applied for 8 years. The investment column in Table II represents the cost of land, fixed capital cost as spent money. The last line indicates the summation of the land, the salvage value, and the working capital recovered after the useful life of the LHS system. Figure 3 shows the DCFD. The revenue and savings are based on the fuel value of the exergy gain by the solar air heater system. The Depreciation $(D)$ is obtained from the straight-line method

$$
D=\frac{\mathrm{FCC}-S}{k}
$$


Table I. A typical approximate local cost data used for discounted cash-flow diagram for seasonal heat storage system. (a) $i=8.0 \%$; (b) $i=5.0 \%$; (c) $i=2.5 \%$.

\begin{tabular}{|c|c|c|c|}
\hline & \multicolumn{3}{|c|}{ Approximate local cost data } \\
\hline & (a) & (b) & (c) \\
\hline $\begin{array}{l}\text { Solar air heater system } \\
\quad \text { Fixed capital cost, } C_{1, \mathrm{~F}}, \$ 6000 \times 18(\$) \\
\text { Operating cost, } \dot{C}_{1, \mathrm{OP}}=0.20 C_{1, \mathrm{~F}}\left(\$ \text { year }^{-1}\right) \\
\text { Total cost } C_{1}(\$)\end{array}$ & $\begin{array}{c}108000 \\
21600 \\
129600\end{array}$ & $\begin{array}{c}108000 \\
21600 \\
129600\end{array}$ & $\begin{array}{c}108000 \\
21600 \\
127440\end{array}$ \\
\hline $\begin{array}{l}\text { Latent heat storage }(\text { LHS }) \text { system } \\
\text { Fixed capital cost, } C_{2, \mathrm{~F}},(\text { steel tank }+ \text { paraffin }+ \text { insulation }+ \text { coil })(\$) \\
\text { Operating cost, } 2 \dot{C}_{2, \mathrm{OP}}, 2\left(0.05 C_{2, \mathrm{~F}}\right)\left(\$ \text { year }^{-1}\right) \\
\text { Total cost, } C_{2}(\$)\end{array}$ & $\begin{array}{c}200000 \\
20000 \\
220000\end{array}$ & $\begin{array}{c}200000 \\
20000 \\
220000\end{array}$ & $\begin{array}{c}200000 \\
20000 \\
218000\end{array}$ \\
\hline $\begin{array}{l}\text { Greenhouse } \\
\quad \text { Fixed capital cost, } C_{3, \mathrm{~F}}(\$) \\
\text { Operating cost, } \dot{C}_{3, \mathrm{OP}},\left(0.20 C_{3, \mathrm{~F}}\right)\left(\$ \text { year }^{-1}\right) \\
\text { Total cost, } C_{3}(\$)\end{array}$ & $\begin{array}{c}95000 \\
19000 \\
114000\end{array}$ & $\begin{array}{c}95000 \\
19000 \\
114000\end{array}$ & $\begin{array}{c}95000 \\
19000 \\
112100\end{array}$ \\
\hline $\begin{array}{l}\text { Total fixed capital cost, } \mathrm{FCC}\left(C_{1, \mathrm{~F}}+C_{2, \mathrm{~F}}+C_{3, \mathrm{~F}}\right)(\$) \\
\text { Total operating cost, }\left(\dot{C}_{1, \mathrm{OP}}+2 \dot{C}_{2, \mathrm{OP}}+\dot{C}_{3, \mathrm{OP}}\right)\left(\$ \text { year }^{-1}\right)\end{array}$ & $\begin{array}{c}403000 \\
60600\end{array}$ & $\begin{array}{r}403000 \\
60600\end{array}$ & $\begin{array}{l}403000 \\
54540^{*}\end{array}$ \\
\hline $\begin{array}{l}\text { Yearly revenues or savings, } \dot{R}\left(\$ \text { year }^{-1}\right) \\
\text { Working capital, } W C,(0.1 \times \mathrm{FCC})(\$) \\
\text { Land, } L(\$) \\
\text { Discount rate } i(\%) \\
\text { Taxation rate: } t(\%) \\
\text { Salvage value } S(\$) \\
\text { Useful life } n \text { (years) } \\
\text { Number of years of depreciation, } k \text { (years) }\end{array}$ & $\begin{array}{c}95000 \\
40300 \\
25000 \\
8 \\
30 \\
20000 \\
12 \\
8\end{array}$ & $\begin{array}{l}95000 \\
40300 \\
25000 \\
5 \\
25 \\
20000 \\
12 \\
8\end{array}$ & $\begin{array}{l}95000 \\
40300 \\
25000 \\
2.5^{*} \\
20^{*} \\
20000 \\
12 \\
8\end{array}$ \\
\hline Net present value, NPV (\$) & -159649.4 & -110498.4 & -4704.4 \\
\hline
\end{tabular}

${ }^{*}$ Reduced operating cost by $10 \%$, and incentives in discount rate and taxation rate.

where FCC is the total fixed capital cost, and $n$ is the useful life assumed as 15 years. The book value (BV) is the capital, which has not yet been depreciated, and estimated from

$$
\mathrm{BV}=\mathrm{FCC}-\sum_{i=1}^{k} D_{i}
$$

where the subscript $k$ is the years subject to depreciation. Non-discounted cash flow after tax is estimated as the net profit + depreciation

$$
\mathrm{NDCF}=\left(R-\mathrm{COP}-D_{k}\right)(1-t)+D_{k} .
$$

where COP is the cost of operation, and $t$ is the tax rate.

The DCFD is based on the approximate local cost rates and the economic data in Table I, and therefore it is sensitive to the costs of fuel, electricity, and exergy as well as the equipment and operation. Annual cash flow is discounted to time zero to find discounted cash flows. The 
Table II. Discounted cash-flow estimations for a seasonal LHS system with low interest rate $i=2.5 \%$, and low tax rate $t=20.0 \%$. Economic data is in Table $\mathrm{I}(\mathrm{c})$.

\begin{tabular}{|c|c|c|c|c|c|c|c|c|}
\hline$n$ & $\begin{array}{c}\text { Investment } \\
\text { (\$) }\end{array}$ & $\begin{array}{c}D \\
\left(\$ \text { year }^{-1}\right)\end{array}$ & $\begin{array}{c}\text { BV } \\
\left(\$ \text { year }^{-1}\right)\end{array}$ & $\begin{array}{c}R \\
\left(\$ \text { year }^{-1}\right)\end{array}$ & $\begin{array}{c}\text { COP } \\
\left(\text { S year }^{-1}\right)\end{array}$ & $\begin{array}{c}\mathrm{NDCF} \\
\left(\$ \text { year }^{-1}\right)\end{array}$ & $\begin{array}{c}\mathrm{DCF} \\
\left(\$ \text { year }^{-1}\right)\end{array}$ & $\begin{array}{c}\mathrm{CCF} \\
\left(\text { Sear }^{-1}\right)\end{array}$ \\
\hline 0 & -25000.0 & 0.0 & 403000.0 & 0.0 & & -25000.0 & -25000.0 & -25000.0 \\
\hline 1 & -403000.0 & 0.0 & 403000.0 & 0.0 & & -443300.0 & -432487.8 & -457487.8 \\
\hline 2 & 0.0 & 47875.0 & 355125.0 & 95000.0 & 54540.0 & 41943.0 & 39922.0 & -417565.9 \\
\hline 3 & 0.0 & 47875.0 & 307250.0 & 95000.0 & 54540.0 & 41943.0 & 38948.2 & -378617.6 \\
\hline 4 & 0.0 & 47875.0 & 259375.0 & 95000.0 & 54540.0 & 41943.0 & 37998.3 & -340619.3 \\
\hline 5 & 0.0 & 47875.0 & 211500.0 & 95000.0 & 54540.0 & 41943.0 & 37071.5 & -303547.8 \\
\hline 6 & 0.0 & 47875.0 & 163625.0 & 95000.0 & 54540.0 & 41943.0 & 36167.3 & -267380.5 \\
\hline 7 & 0.0 & 47875.0 & 115750.0 & 95000.0 & 54540.0 & 41943.0 & 35285.2 & -232095.3 \\
\hline 8 & 0.0 & 47875.0 & 67875.0 & 95000.0 & 54540.0 & 41943.0 & 34424.6 & -197670.7 \\
\hline 9 & 0.0 & 47875.0 & 20000.0 & 95000.0 & 54540.0 & 41943.0 & 33584.9 & -164085.8 \\
\hline 10 & 0.0 & 0.0 & 20000.0 & 95000.0 & 54540.0 & 32368.0 & 25285.8 & -138800.0 \\
\hline 11 & 0.0 & 0.0 & 20000.0 & 95000.0 & 54540.0 & 32368.0 & 24669.1 & -114130.9 \\
\hline 12 & 0.0 & 0.0 & 20000.0 & 95000.0 & 54540.0 & 32368.0 & 24067.4 & -90063.4 \\
\hline 13 & $85300.0^{*}$ & 0.0 & 20000.0 & 95000.0 & 54540.0 & 117668.0 & 85358.8 & -4704.7 \\
\hline
\end{tabular}

*\$83 $500=$ land cost + salvage value + working capital.

$D$ : depreciation: straight-line method: $D=(\mathrm{FCC}-S) / k$.

$\mathrm{BV}$ : book value: $\mathrm{BV}=\mathrm{FCC}-\sum\left(D_{k}\right)$.

NDCF: non-discounted cash flow: net profit + depreciation: $\left(R-\operatorname{COP}-D_{k}\right)(1-t)+D_{k}$.

$R$ : revenue and saving.

COP: cost of production.

DCF: discounted cash flow.

CCF: cumulative cash flow.

cumulative discounted cash flows yield a net present value (NPV). NPV shows the cumulative discounted cash value at the end of useful life of a system. A NPV of $-\$ 159649$ is obtained at end of 12 years of useful life operation of the LHS system when discount rate $i=8 \%$ and tax rate $t=30 \%$ (Figure 3(a)), while the value of NPV is $-\$ 110498$ for $i=5 \%$ and $t=25 \%$ (Figure 3(b)). Similar CFDs can also be prepared for individual units.

Because, DCFDs display the cash flows over the years of operation based on the current economic values, such as interest rates, taxation, and the cost rates of fuel, it may enhance the impact of the thermoeconomic approach in design and operation of thermal systems. Beside that, DCFDs based on exergy incorporate the true potential of energy. Consequently, DCFDs may help evaluating the profitability of a design and operation. It may also help quantifying the monetary gains of environmentally friendly systems and utilization of renewable exergy. The profitability criteria may be obtained in terms of payback period (PBP) and NPV. PBP is the time required, after the construction, to recover the fixed capital investment. Positive values of NPV and shorter PBP are preferred (Turton et al., 2003) for a feasible design and operation. Savings due to the use of solar exergy, the CFD maintains a positive slope. Provided that the fixed capital cost is lowered, and with the monetary intensives due to environmental friendly technologies, a profitable LHS system with positive NPV and an acceptable PBP can be achieved (Frangopoulos and Caralis, 1997; Sciubba, 2003). For example, by lowering the operating costs by $10 \%$ due to increased exergy efficiency, and assuming the low rates of $i=2.5 \%$ 

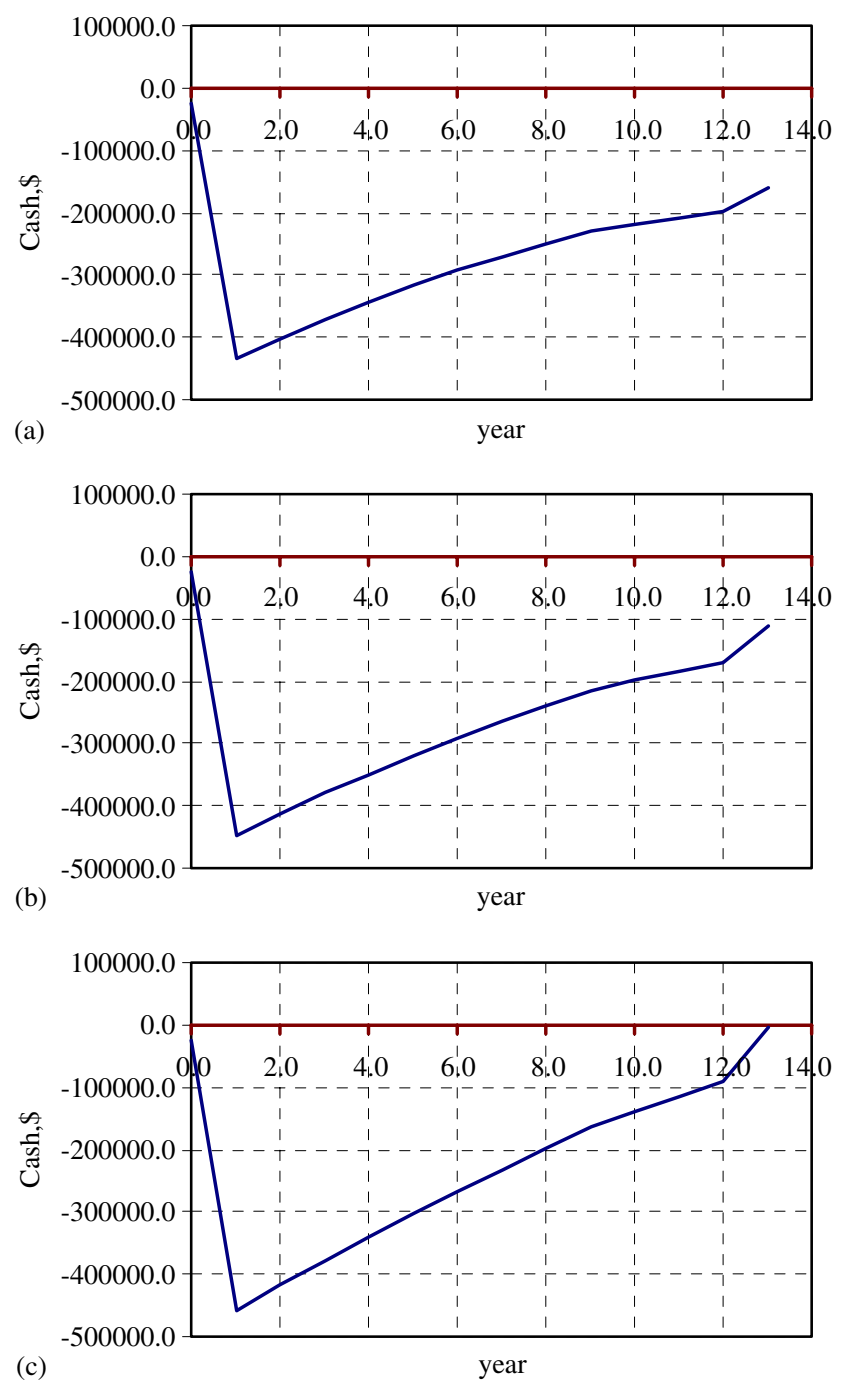

Figure 3. (a) Discounted cash-flow diagram for the LHS system: (a) $i=8.0 \%$, and $t=30.0 \%$; (b) $i=5.0 \%$, and $t=25.0 \%$; and (c) $i=2.5 \%$, and $t=20.0 \%$ and $\sum \dot{C}_{i, \mathrm{OP}}=\$ 54540$ year $^{-1}$.

and $t=20 \%$ as incentives for using renewable energy, NPV becomes $-\$ 4704.4$, as shown in Figure 3(c). This level of NPV makes the LHS system feasible.

\section{CONCLUSIONS}

Thermoeconomic analysis accounts the cost of exergy within the economic analysis to obtain feasible design and operating conditions. Exergy analysis takes into account the true potential of 
energy. The cost rate balance based on a product of a unit enables one to estimate the specific cost of a product based on exergy or ratio of exergies. Discounted cash-flow diagrams incorporating the cost rate of exergy may enhance the impact of thermoeconomic analysis as it displays the exergy and time value of the money, and help determining the feasibility of overall design and operation of thermal systems.

\section{NOMENCLATURE}

\begin{tabular}{|c|c|}
\hline$c$ & $=$ specific cost $\left(\$ \mathrm{~W}^{-1}\right)$ \\
\hline$C$ & $=\operatorname{cost}\left(\$\right.$ year $\left.^{-1}\right)$ \\
\hline$C_{p}$ & $=$ specific heat $\left(\mathrm{kJ} \mathrm{kg}^{-1} \mathrm{~K}^{-1}\right)$ \\
\hline CFD & $=$ cash-flow diagram \\
\hline$D$ & $=$ depreciation $\left(\$\right.$ year $\left.^{-1}\right)$ \\
\hline DCFD & $=$ discounted cash-flow diagra \\
\hline FCC & $=$ fixed capital cost $(\$)$ \\
\hline$H$ & $=$ melting enthalpy $\left(\mathrm{kJ} \mathrm{kg}^{-1}\right)$ \\
\hline$i$ & $=$ rate of interest $(\%)$ \\
\hline$L$ & $=$ cost of land $(\$)$ \\
\hline LHS & $=$ latent heat storage \\
\hline$\dot{m}$ & $=$ mass flow rate $\left(\mathrm{kg} \mathrm{s}^{-1}\right)$ \\
\hline$n$ & $=$ useful life (year) \\
\hline PCM & $=$ phase-changing material \\
\hline$\dot{Q}$ & $=$ heat flow $(\mathrm{W})$ \\
\hline$R$ & $=$ revenue $\left(\$\right.$ year $\left.^{-1}\right)$ \\
\hline$S$ & $=$ salvage value $(\$)$ \\
\hline$t$ & $=$ time, $\mathrm{s} ;$ rate of taxation $(\%)$ \\
\hline$T$ & $=$ temperature $(\mathrm{K})$ \\
\hline$T_{1}$ & $=$ lowest melting point $(\mathrm{K})$ \\
\hline$T_{\mathrm{h}}$ & $=$ highest melting point $(\mathrm{K})$ \\
\hline$\dot{W}$ & $=$ work $(\mathrm{W})$ \\
\hline$\dot{X}$ & $=$ rate of exergy $(\mathrm{W})$ \\
\hline$\eta$ & $=$ efficiency \\
\hline
\end{tabular}

\section{Subscripts}

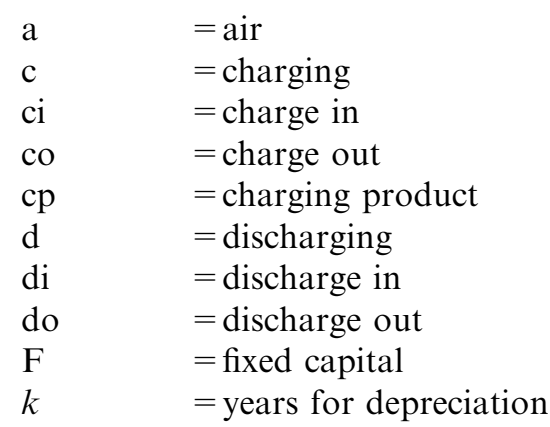




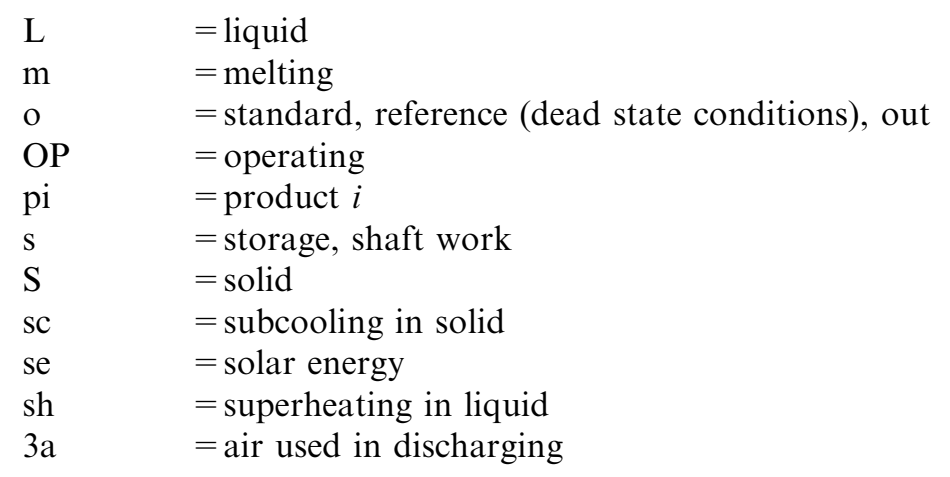

\section{REFERENCES}

Bascetincelik A, Ozturk HH, Paksoy HO, Demirel Y. 1999. Energetic and exergetic efficiency of latent heat storage system for greenhouse heating. Renewable Energy 16:691-694.

Demirel Y. 1989. Experimental investigation of heat transfer in a packed duct with unequal wall temperatures. Experimental Thermal Fluid Science 2:425-431.

Demirel Y. 2002. Nonequilibrium Thermodynamics: Transport and Rate Processes in Physical and Biological Systems. Elsevier: Amsterdam; 186-205.

Demirel Y, Bascetincelik A, Paksoy HO, Oztekin S. 1993. The use of seasonal heat storage in greenhouse air conditioning. ITEC-93, First International Thermal Energy Congress, Marrakesh, Morocco. 6-10 June, 889-892.

Demirel Y, Kunç S. 1987. Thermal performance study on a solar air heater with packed flow passage. Energy Conversion and Management 27:317-325.

Demirel Y, Paksoy HO. 1993. Thermal analysis of heat storage materials. Thermochimica Acta 213:211-221.

Erlach B, Serra L, Valero A. 1999. Structural theory as standard for thermoeconomics. Energy Conversion and Management 40:1627-1649.

Frangopoulos CA, Caralis YC. 1997. A method for taking into account environmental impacts in the economic evaluation of energy systems. Energy Conversion and Management 38:1751-1763.

Go Z, Liu H, Li Y. 2004. Thermal energy recovery of air conditioning system-heat recovery system calculation and phase change materials development. Applied Thermal Engineering 24:2511-2526.

Lin K, Zhang Y, Xu X, Di H, Yang R, Qin P. 2005. Experimental study of under-floor electric heating system with shape-stabilized PCM plates. Energy and Buildings 37:215-220.

Ozturk HH. 2005. Experimental evaluation of energy and exergy efficiency of a seasonal latent heat storage system for greenhouse heating. Energy Conversion and Management 46:1523-1542.

Ozturk HH, Demirel Y. 2004. Exergy-based performance analysis of packed-bed solar air heaters. International Journal of Energy Research 28:423-432.

Ramayya AV, Ramesh KN. 1998. Exergy analysis of latent heat storage system with sensible heating and subcooling of PCM. International Journal of Energy Research 22:411-426.

Rosen MA, Dincer I. 2003. Exergy methods for assessing and comparing thermal storage systems. International Journal of Energy Research 27:415-430.

Saman W, Bruno F, Halawa E. 2005. Thermal performance of PCM thermal storage unit for a roof integrated solar heating system. Solar Energy 78:341-349.

Sciubba E. 2003. Cost analysis of energy conversion systems via a novel resource-based quantifier. Energy 28:457-477.

Szargut J. 1990. In Finite-Time Thermodynamics and Thermoeconomics, Sieniutcyz S, Salamon P (eds). Taylor \& Francis: New York.

Tsataronis G. 1993. Thermoeconomic analysis and optimization of energy systems. Progress in Energy and Combustion Systems 19:227-257.

Turton R, Bailie RC, Whiting WB, Shaeiwitz JA. 2003. Analysis, Synthesis, and Design of Chemical Processes (2nd edn). Prentice-Hall: Upper Saddle River; 221-308.

Valero A, Lozano MA, Serra L, Torres C. 1994. Application of the exergetic cost theory to the CGAM problem. Energy 19:365-372. 